\title{
Configurações
}

Revista de sociologia

$11 \mid 2013$

Território e Desenvolvimento

\section{Capital social como instrumento de desenvolvimento sustentável}

Social capital as a tool for the sustainable development

Capital social comme instrument du dédeloppement soutenable

\section{Eduardo Duque}

\section{OpenEdition}

\section{Journals}

\section{Edição electrónica}

URL: http://journals.openedition.org/configuracoes/1862

DOI: $10.4000 /$ configuracoes. 1862

ISSN: 2182-7419

\section{Editora}

Centro de Investigação em Ciências Sociais

\section{Edição impressa}

Data de publição: 1 Junho 2013

Paginação: 189-201

ISBN: 1646-5075

ISSN: 1646-5075

\section{Refêrencia eletrónica}

Eduardo Duque, «Capital social como instrumento de desenvolvimento sustentável », Configurações [Online], 11 | 2013, posto online no dia 22 setembro 2014, consultado o 30 abril 2019. URL : http:// journals.openedition.org/configuracoes/1862 ; DOI : 10.4000/configuracoes.1862

Este documento foi criado de forma automática no dia 30 Abril 2019.

(c) CICS 


\title{
Capital social como instrumento de desenvolvimento sustentável
}

\author{
Social capital as a tool for the sustainable development \\ Capital social comme instrument du dédeloppement soutenable
}

\author{
Eduardo Duque
}

\section{Introdução}

1 São vários os autores que tratam o capital social como um recurso necessário $\mathrm{e}$ imprescindível para a configuração de um desenvolvimento sustentável, na medida em que é capaz de promover a interação entre pessoas, estruturas e instituições, sustentadas pela confiança mútua e cooperação, pelo civismo e participação.

2 A ideia base que subjaz a este princípio é a de que, havendo a agilização das redes sociais, estimuladas pela confiança e cooperação, há um benefício direto em prol do social, sendo que, ao invés, o não aproveitamento daquelas sinergias conduz a uma condição social reducionista. Esta teoria aparece bem vincada em Putnam (1995) quando refere que, numa sociedade com forte expressão de capital social, o compromisso cívico, assumido pelas redes sociais, impulsionará uma atitude de reciprocidade e, consequentemente, o revigoramento da confiança mútua.

3 A ideia de capital social tem-se vindo a tornar cada vez mais imperiosa numa sociedade que, segundo Coleman (1990), se apresenta como um conjunto de indivíduos independentes, que visam objetivos meramente pessoais, em detrimento dos interesses coletivos. Neste contexto, o capital social é uma resposta de inteligência social que promove processos de cooperação, de ação coletiva, que se opõe ao individualismo social.

4 Assim sendo, que mais-valias aporta o capital social ao desenvolvimento sustentável? Se entendermos o desenvolvimento sustentável como um processo contínuo em que as preocupações humanas, sociais e ambientais visam a melhoria das condições de vida dos cidadãos, compreende-se que a sua exequibilidade dependa de fatores decisivos, tais como 
o envolvimento e a corresponsabilização das populações enquanto agentes de desenvolvimento local.

5 São as populações locais concretas que precisam de mover o seu próprio capital social, já que o desenvolvimento sustentável de uma região nasce à escala local, dependendo das dinâmicas dos indivíduos que, desenvolvendo capacidades cooperativas e participativas, se associam em objetivos comuns.

6 Esta visão do capital social, como elemento nuclear para o desenvolvimento sustentável ao nível local, alicerça-se no princípio de que este desenvolvimento procede do contexto endógeno que lhe é inerente; daí que, qualquer transformação económica, social ou política seja fruto de relações de reciprocidade, cooperação, confiança e entendimento entre os diferentes atores locais.

7 Este estudo está dividido em dois capítulos: no primeiro capítulo procede-se a uma revisão muito breve das noções fundamentais do capital social, sendo que o segundo capítulo é dedicado à apresentação da metodologia e dos principais resultados.

\section{Capital Social como "arte de saber partilhar"}

8 Nos últimos anos produziu-se um crescente interesse dos académicos pela temática do capital social. De um modo particular, relacionou-se o capital social com diferentes realidades, como o crescimento económico (Helliwell e Putman, 1995; Knack e Keefer, 1997), a eficiência do sistema judicial (La Porta et al., 1997), a mobilidade laboral (DiPasquale e Glaeser, 1999), as instituições (Bowles e Gintis, 2002), a expansão da educação (Goldin e Katz, 2001) e o desenvolvimento do sistema fi nanceiro (Guiso et al., 2004).

9 Na verdade, a noção de capital social surge como uma resposta a um dos mais decisivos mitos fundadores da civilização moderna: o de que a sociedade é um "conjunto de indivíduos independentes, cada um agindo para alcançar objetivos a que chegam independentemente uns dos outros, o funcionamento do sistema social consistindo na combinação destas ações dos indivíduos independentes" (Coleman, 1990: 300).

A literatura científica e os diferentes relatórios de agências internacionais que trabalham questões ligadas ao capital social partem, de forma geral, da constatação de que os atores económicos não são por si só suficientes para gerar crescimento socialmente justo e ambientalmente sustentável. Referem, por isso, que o crescimento económico não conduz, necessária e diretamente, ao desenvolvimento social. E, desta forma, retomam o princípio de que as instituições e as estruturas sociais são elementos decisores aquando do acesso aos benefícios económicos produzidos e da sua repartição ${ }^{1}$.

11 Compreende-se, assim, que o termo capital social tenha estado sujeito a uma discussão bastante alargada. Entre muitos autores, Putman (1995) surge com uma conceção que sobressai entre os demais, salientando que o capital social é uma série de características das organizações sociais, tais como as relações, as normas e a confiança social, que facilitam a coordenação e a cooperação para conseguir o benefício mútuo. Ou seja, capital social é o conjunto de interações das pessoas e das associações sociais e produtivas envolvendo ordenamento, redes sociais, liderança, cooperação, civismo, reciprocidade de favores e confiança que contribuem para que as pessoas atinjam objetivos e metas comuns. 
12 Desta forma, as estruturas sociais devem ser entendidas como plataformas de diálogo que alimentam tanto a capitalização como a prospetiva dos indivíduos que a elas recorrerem. o capital social, entendido assim, não é uma entidade individual, mas uma pluralidade de entidades com dinâmicas diferenciadas que, em diálogo, se propõem compreender a história de cada estrutura social, facilitando, assim, as ações dos indivíduos que a integram, em ordem à evolução dos seus posicionamentos. Desta forma, o capital social é produtivo, já que ele torna possível que se alcancem objetivos que não seriam atingidos na sua ausência.

13 A complexidade da sua análise levou a que muitos autores se pronunciassem sobre a problemática do capital social.

14 A origem do interesse recente no capital social pode ser em parte traçada no trabalho teórico de Pierre Bourdieu. No final dos anos de 1960 e início de 1970, Bourdieu produziu uma série de estudos caracterizando a cultura como um fenómeno dinâmico e criativo, mas também estruturado. Para ele o capital económico está na raiz de todos os outros tipos de capital e constitui a casa para a qual toda acumulação eventualmente retorna. Mas apesar da primazia do económico, Bourdieu debruça-se intensamente, nos seus trabalhos empíricos e teóricos, sobre o capital "simbólico".

O interesse no conceito de capital social emergiu gradualmente no trabalho de Bourdieu, no início como uma metáfora ligada a outras formas de capital e, apenas mais tarde, como um conceito em si. À procura de teorias sobre a reprodução das relações de classes sociais mediadas por mecanismos culturais, Bourdieu atribuiu lugar de destaque ao capital social na sua análise, mas não o aprofundou conceitualmente. A primeira vez que este autor recorre a este termo remonta ao início da década de 1980, para se referir às vantagens e oportunidades de se pertencer a certas comunidades. A partir de então, define capital social como o conjunto de "recursos reais ou potenciais que se vinculam à participação numa rede estável de relações mais ou menos institucionalizadas de recíproca convivência e reconhecimento (...) que provê para cada um de seus membros o suporte do capital de propriedade coletiva" (Bourdieu, 1983: 51, apud Baron, Field e Schüller, 2000).

O trabalho do sociólogo James Coleman sobre capital social foi particularmente influente nos países de língua inglesa e derivou do seu interesse em associar as abordagens da sociologia e da economia. Como outras formas de capital, assinala Coleman, o capital social é produtivo, possibilitando o alcance de certos fins que não seriam possíveis na sua ausência. Para o autor, capital social é definido pela sua função. Não é uma entidade individual, mas uma diversidade de estruturas diferenciadas, que partilham dois objetivos: são todos consistentes com alguns aspetos das estruturas sociais e facilitam certas ações dos atores - sejam pessoas ou empresas - no âmbito da estrutura (Coleman, 1988).

Coleman refere-se a três distintas formas de capital social. A primeira lida com o nível de confiança e a real extensão das obrigações existentes em determinado ambiente social. 0 capital social, neste caso, é elevado, uma vez que existe confiança entre os pares e essa mesma confiança é repartida pela concordância mútua de deveres. A segunda forma diz respeito a canais de trocas de informações e ideias, particularmente, à vantagem da permuta de informações essenciais para elaborar e validar estratégias. A terceira e última forma refere-se às normas e sanções que integram o capital social, na medida em que estimulam os indivíduos a dedicar-se à causa comum, rejeitando proveitos próprios imediatos. 
Um dos autores mais citados sobre o tema em questão é o cientista político Robert Putnam, que, a partir de 1970, estudou e aprofundou esta temática a partir da análise da sociedade civil em Itália e nos Estados Unidos.

Putnam refere-se ao capital social como atributos próprios das organizações sociais, como sejam as redes, as normas e a confiança, que mais não são do que facilitadores da ação e cooperação tendo em vista o benefício mútuo.

Como refere o mesmo autor, trabalhar em parceria torna-se mais fácil numa comunidade com uma quantidade substancial de capital social (Putnam, 1993: 35-36).

Robert Putnam sublinha ainda que num grupo ou numa sociedade com um valor significativo de capital social, as redes sociais de compromisso cívico estimulam a prática generalizada de confiança recíproca, facilitando a confiança mútua (Putnam, 1995: 67).

Neste sentido, e tendo em conta a análise apresentada pelos vários autores, de um modo particular por este último, compreende-se o princípio de que para haver desenvolvimento local é necessário o envolvimento de fatores sociais, culturais e políticos que não se regulam exclusivamente pelo sistema de mercado. O crescimento económico é uma dimensão essencial, todavia, não suficiente para conduzir ao desenvolvimento local sustentável.

3 Esta pluralidade de visões sociológicas sobre o capital social tem investido nas potenciais vantagens disponibilizadas aos seus interlocutores em virtude da sua integração e interação em redes de maior amplitude. Muitos atores de grande capacidade de influência de massas, particularmente políticos, provocaram uma alteração conceptual de relevância acentuada, ao fazerem corresponder o capital social ao "civismo", quer com dinâmicas transversais a países inteiros, quer a nível local.

Na verdade, o desenvolvimento local é marcado pela cultura cidadã do contexto em que se enquadra, não se restringindo ao impacto de uma ou de duas variáveis de maior relevo, como a social ou a económica. A realidade é bem mais complexa, pelo que faz com que o desenvolvimento local seja o resultado da ação de estratégias conjuntas de atividades sociais, políticas, económicas e culturais que participam reciprocamente na transformação da realidade local. Nesta perspetiva de transformação social há um nível considerável de correlação e interdependência entre as diversas dimensões e segmentos que constituem a sociedade - referimo-nos tanto à dimensão política e educativa, como à económica e ambiental ou à tecnológica e cultural. Todas elas se revestem de carácter imprescindível quando se procura o bom funcionamento da sociedade.

Compreende-se, assim, neste contexto, que para haver desenvolvimento local é necessário que se criem redes sociais que promovam a confiança, a cooperação e a responsabilidade. Esta evidência levanta uma questão premente: como promover o capital social em prol do desenvolvimento sustentável numa localidade específica? Neste artigo, pretende-se discutir o capital social como recurso que pode contribuir para a construção desse processo, porque gera ação e inteligência social, como resultado das interações entre as pessoas e as instituições sociais, num processo de ida e vinda de informações e conhecimento que facilita a solução de problemas. O nível de capital social numa determinada comunidade ou região depende da habilidade dos indivíduos de se associarem em objetivos comuns, compartilhando normas e interesses (Wolfe, 2002).

Cremos ser de senso comum que, para que haja desenvolvimento, as regiões e comunidades menos favorecidas devem ser fortalecidas de capital social, pois o 
desenvolvimento sustentável de um país nasce ao nível local, propiciando alternativas culturais, económicas e sociais à população.

Reconhece-se, assim, que o desenvolvimento sustentável requer a junção de toda uma panóplia de fatores, já por nós evidenciados, de modo a que se obtenha êxito nas políticas de desenvolvimento, pois os problemas e desafios por que passam as pequenas localidades, sobretudo em meios rurais, são cada vez mais complexos, e somente uma visão economicista, baseada em números, não é suficiente para explicar os fenómenos sociais por que passam determinadas cidades, regiões ou comunidades. o nível de capital social nas comunidades pode ser um dos indicadores de desenvolvimento, na medida em que estabelece a capacidade participativa e cooperativa das pessoas. Deste modo, se este é um caminho alternativo ao desenvolvimento sustentável, então como forma de se obter elevados níveis de capital social é necessário investir-se em capital humano - nomeadamente na qualidade das respostas ao nível da saúde e da educação. Capital social gera capital humano e este gera aquele. De certa forma, quando o governo investe em educação de qualidade e saúde, está a criar espaço social para a formação de capital social em níveis mais elevados.

Para Boisier (1997, apud Moreira, 2008), a sociedade desempenha uma função primordial na transformação socioeconómica de um local ou região, através do fortalecimento de alguns princípios basilares de convivências, nomeadamente de solidariedade, de integração social e de compromisso cívico.

Esta visão concertada de desenvolvimento económico e rentabilidade sociocultural dos habitantes de uma localidade pode, na nossa opinião, ser o caminho a percorrer em prol do seu desenvolvimento sustentável.

De um modo mais alargado, podemos concluir que o capital social é um recurso fundamental que pode apoiar a construção de um sistema produtivo ambientalmente viável e contribuir para o bem-estar social (saúde, educação, segurança pública, aprendizagem social, inovação tecnológica e justiça social) através da formação de redes sociais que possam expandir a cooperação e o nível de cooperação, num plano onde a economia se aproxime da ética.

Sendo assim, desenvolvimento sustentável é um termo abrangente que incorpora as diversas dimensões da realização pessoal dos membros dos diferentes grupos populacionais. Ele vai muito além do crescimento económico, embora este seja um requisito fundamental para se alcançar aquele. Inclui dimensões como liberdade de expressão e direitos às diversas formas de dignidade nas relações sociais, associadas a um mínimo de acesso a bens e serviços disponíveis a outros grupos populacionais ou a outros membros do seu grupo. A sustentabilidade do desenvolvimento está associada ao grau de agressão à natureza que as diferentes tecnologias implicam e à manutenção das taxas de crescimento induzidas por novos investimentos em algum nível de capital.

Embora quase toda a atividade económica implique alguma agressão ao meio ambiente, a qualidade de vida das gerações futuras não pode ser comprometida quando pretendemos esse desenvolvimento.

O conceito de desenvolvimento sustentável, impulsionado por diferentes acontecimentos preocupantes, nomeadamente, os acidentes nucleares, a desertificação de grandes áreas do planeta, as marés negras, as chuvas ácidas, o buraco do ozono, entre outros, foi-se alargando à medida que o homem refletia sobre o seu futuro e o do planeta. A noção de que o caminho que estava a ser traçado trazia prejuízos irrecuperáveis ao homem levou a 
que se sentisse a necessidade de pensar num desenvolvimento diferente, isto é, que se pensasse na melhoria das condições económicas, sociais e ambientais da região e das populações autóctones, sem pôr em causa as condições necessárias ao desenvolvimento das gerações futuras (Antunes, 2001).

Vários foram os momentos em que se assistiu a uma preocupação crescente com as questões de sustentabilidade, bem expressa na realização de Conferências Mundiais promovidas pelas Nações Unidas (Estocolmo em 1972, Rio de Janeiro em 1992, Quioto em 1997 e Joanesburgo em 2002). A nível nacional, a adoção de medidas que promovessem fatores como a saúde, a educação, a esperança de vida e o ambiente revelar-se-ia como um contributo para um problema global, cada vez mais indiferente às fronteiras políticas, devido a outro fenómeno: o da globalização.

Toda esta abordagem do tema assentava apenas em dois pilares fundamentais: o desenvolvimento económico e a proteção do ambiente. No entanto, é com a Cimeira de Copenhaga (1995) que se inclui a vertente social como terceiro pilar do conceito de desenvolvimento sustentável. Neste contexto, a implementação do desenvolvimento sustentável começa a assentar em três pilares fundamentais: o desenvolvimento económico, $a$ coesão social e a proteção do ambiente. A estes três pilares dever-se-á acrescentar, ainda, a dimensão institucional, que alerta para as questões que dizem respeito à governação, às instituições e aos sistemas legislativos e à participação de grupos de interesse e da sociedade civil, considerados como parceiros fundamentais na promoção de um desenvolvimento sustentável. Pilares que são reforçados na Conferência Mundial sobre Desenvolvimento Sustentável, realizada em Joanesburgo, em 2002.

É nesta visão alargada de desenvolvimento sustentável que se compreende o lugar que o capital social ocupa na sociedade moderna.

"É importante que os processos locais de desenvolvimento sejam percebidos como recursos estratégicos e possam ser vistos como uma oportunidade de transformação local. A compreensão do local, enquanto espaço de produção e de valorização do capital social, humano e cultural, é de extrema importância para o desenvolvimento económico e social" (Pereira, 2007: 302).

\section{Metodologia e principais resultados}

A questão com que agora nos deparamos prende-se com a forma como se poderá analisar o capital social, bem como a sua operacionalização.

Dado que neste estudo se pretende perceber de que forma o capital social interfere no desenvolvimento sustentável, propomo-nos analisar as dimensões implicadas no capital social circunscrevendo-as a Portugal. Para tal, recorreremos a uma análise longitudinal, entre 1990 e 2008, a partir dos dados do European Values Survey (EVS), inquérito fundado em 1978, pela Fundação Europeia, para o estudo dos valores.

41 Como medida desse capital, evocaremos alguns dos seus elementos centrais, como a confiança social, as normas de reciprocidade e a participação nas redes sociais, já que estas dimensões, em conjunto, permitem compreender a forma como os indivíduos constroem o mesmo bem comum.

Uma vez que optamos por trabalhar com dados do EVS, e de forma longitudinal, recorremos às seguintes variáveis para medir as dimensões já referenciadas. A confiança 
social é medida segundo duas perspetivas: por um lado, a confiança entre pares, analisada através da questão "De uma forma geral, acha que se pode confiar na maioria das pessoas ou, pelo contrário, acha que todo o cuidado é pouco?"2; por outro, a confiança institucional, a partir da questão "Das seguintes instituições, diga, por favor, qual o grau de confiança que lhe inspira cada uma delas"3. Para a análise da dimensão das normas de reciprocidade, que representa a atitude cívica que cada indivíduo aporta ao seu meio comunitário, recorreu-se a uma bateria de questões relativas à justificação de comportamentos: "reivindicar benefícios do Estado a que não se tem direito", "não pagar impostos se tiver oportunidade", "apropriar-se do carro de outra pessoa, sem lhe pedir licença, para dar uma volta", "mentir no seu próprio interesse" e "aceitar um suborno no cumprimento dos seus deveres"4. Por último, a participação em redes sociais é medida a partir de dois prismas, sendo o primeiro a importância atribuída às redes informais, objetivado a partir da relevância dada aos amigos e conhecidos na vida ${ }^{5}$, e o segundo prisma incidindo na análise do grau de envolvimento em redes formais, nomeadamente na participação e na prática de voluntariado em organizações ${ }^{6}$.

43 As questões que integram as dimensões aqui apresentadas serão trabalhadas não de forma independente, mas agregadas numa medida global de capital social, a qual foi calculada da seguinte forma: a baixos níveis de confiança nas instituições e entre pares, a justificação de comportamentos pouco cívicos e a fraca participação em redes sociais formais e informais corresponde um baixo nível de capital social (1); no extremo oposto a estas posições, encontram-se os indivíduos com nível alto de capital social (5).

Com a análise desta medida global de capital social, pretende-se indagar até que ponto a sociedade portuguesa se envolveu de forma comprometida com questões de promoção do bem comum e se esta postura poderá contribuir para o desenvolvimento económico, social e ambiental sustentável de uma localidade. Pretende-se ainda analisar quem são os portugueses que apresentam valores mais elevados de capital social.

me dos dados é o baixo nível de capital social que os portugueses, na sua generalidade, manifestam: em 1990, os portugueses apresentam um valor de 1,8 de capital, numa escala de 1 a 5; em 1999, 1,7 e, em 2008, aquele valor sobe uma décima, para $1,9^{7}$.

46 Este baixo nível de capital social não é estranho, já que, se analisarmos as respostas dos inquiridos no mais recente Estudo Europeu dos Valores, observamos que, em relação à questão que mede a confiança em relação aos outros, $80 \%$ dos portugueses referem que, em relação aos outros, "todo o cuidado é pouco", o que deixa transparecer um baixo nível de confiança nas pessoas. Por sua vez, também as instituições e organizações apresentam escassos níveis de crédito, o que pode configurar uma fraca participação dos indivíduos na vida associativa e, naturalmente, um fraco envolvimento no voluntariado. Note-se que $80 \%$ dos inquiridos, em 2008, referem que não fazem parte de qualquer organização e cerca de $86 \%$ não exercem qualquer atividade voluntária.

Sabemos que a confiança e abertura ao outro gera laços associativos. Ora a nossa questão seria, como é possível esta abertura ao outro, ao social, ao meio sem uma atitude de cooperação? Tocqueville (2006), em a Democracia na América, observava que, contrariamente à França, os EUA possuíam uma rica "arte da associação", isto é, uma população habituada a juntar-se em associações voluntárias com propósitos que tanto podiam ser triviais como sérios. A democracia americana e o seu sistema de governo limitado só funcionavam porque os americanos eram tão adeptos de formarem associações com fins civis ou políticos. Esta forma de organização não representava 
somente que o governo não tinha de impor a ordem de uma forma hierárquica, de cima para baixo; a associação civil era igualmente uma "escola de autogovernação" que ensinava às pessoas hábitos cooperativos que podiam levar consigo para a vida pública (Fukuyama, 2000). Terão os portugueses consciência de que a capacidade associativa e de confiança é crucial para a criação de uma sociedade civil onde todos se sintam perfeitamente enquadrados? A fraca participação na vida associativa pode querer representar que os indivíduos não têm interesses comuns, vivem a sua vida concentrados em si próprios sem se preocuparem com o bem comum, daí resultando a falta de luta e de empenho em causas emergentes. Na realidade, a fraca participação e a débil capacidade de nos associarmos podem deixar antever que é mais fácil viver numa atitude passiva perante o social do que numa atitude comprometida, em que cada um se sinta implicado nas causas de todos, habituando-se, desde cedo, ao exercício de se juntar a outros em defesa dos mesmos interesses.

Não obstante estes valores baixos de capital social, é importante compreender quem são os portugueses que têm assumido uma postura de maior comprometimento com o social. Para tal, procedemos à análise da sociedade portuguesa a partir de algumas variáveis sociodemográficas, como o sexo, a idade, o nível de rendimento, a dimensão do aglomerado e a idade em que se deixou de estudar.

Ao tentarmos perceber se haveria diferenças de capital entre homens e mulheres, observou-se que, em qualquer um dos três anos em estudo, as diferenças não eram significativas; ; porém, ao observar a idade e o nível de rendimento, encontramos tendencialmente maior capital social nas gerações mais novas ${ }^{9} \mathrm{e}$ com mais rendimentos ${ }^{10}$. Fukuyama (2000) referia que as verdadeiras comunidades estão ligadas por valores, normas e experiências partilhadas pelos seus membros. Seria portanto de esperar que nos meios mais pequenos, onde existem fortes laços tradicionais, onde as famílias se conhecem e partilham expectativas e relacionamentos mais profundos, se encontrasse um sentimento de comunidade mais profundo. Se assim fosse, seria de esperar que, nos meios mais pequenos, encontrássemos maiores valores de capital social. Todavia, no nosso estudo, tal não acontece, o que se traduz, à exceção de 1999, em diferenças não significativas de capital entre as diferentes dimensões dos aglomerados ${ }^{11}$.

51 Ao analisarmos o capital social por nível de instrução, partimos do princípio de que as pessoas com mais elevado nível académico são as que reúnem mais habilidades para se auto-organizarem, estabelecerem redes sociais e praticarem a reciprocidade. Tal facto manifesta-se no nosso estudo, já que se observam maiores valores de capital social nos portugueses cuja idade em que pensaram deixar os estudos era mais avançada. Daí que, na nossa escala, sejam os que pensavam em deixar os estudos com 21 ou mais anos que apresentam maiores valores de capital social ${ }^{12}$.

\section{Conclusão}

52 Esta análise longitudinal e sociodemográfica da sociedade portuguesa leva-nos a concluir sobre a pertinência de se abordar a temática do capital social como instrumento de desenvolvimento sustentável. Neste estudo não se analisa estatisticamente o desenvolvimento sustentável, mas a literatura apresentada releva a importância que o capital social tem na promoção desse desenvolvimento, na medida em que se fomenta a 
capacidade participativa e cooperativa das pessoas e as responsabiliza pelo desenvolvimento da sua localidade. túnel: os dados aqui apresentados realçam o facto de que, quanto maior o nível de escolaridade ou quanto mais tarde se terminarem os estudos, maior é o capital social desse indivíduo e, quanto maior for o capital social maior será o desenvolvimento. Este indicador permite-nos antever que a sociedade portuguesa poderá vir a ter uma atitude diferente perante o bem comum, na medida em que as gerações portuguesas mais jovens têm tido a oportunidade de estudar até mais tarde e, desta forma, têm a oportunidade de adquirir uma consciência mais alargada e mais bem formada sobre o papel que devem assumir na sociedade. tomou consciência das mais-valias que o investimento pessoal na confiança mútua nas redes sociais e na reciprocidade poderão trazer ao desenvolvimento económico de uma localidade e consequentemente à prosperidade das gerações futuras. A média em Portugal de capital social de 1,9, em 2008 (numa escala de 1 a 5), evidencia que ainda estamos muito longe de vislumbrar qual a mais-valia do capital social no desenvolvimento sustentável de uma localidade. 


\section{BIBLIOGRAPHY}

BAKER, W. E. (1990), "Market networks and corporate behaviour", American Journal of Sociology, 96: 589-625.

BOURDIEU, P. (1980), "Le capital social: notes provisoires", Actes de la Recherche en Sciences Sociales, 31: 2-3.

BOURDIEU, P. (1983), "The forms of capital”, in A. H. Halsey, et al. (Eds.) Education, Culture Economy and Society, Oxford: Oxford University Press.

BOURDIEU, P. (1985), “The forms of capital”, in J. G. Richardson (org.), Handbook of Theory and Research for the Sociology of Education, Nova Iorque, Greenwood, pp. 241-258.

BOURDIEU, P.; PASSERON. J. C. (1970), "La reproduction. Paris: Les Editions de Minuit”, in St., Baron; J. Field; T. Schuller, (Ed.) (2000), Social Capital: Critical Perspectives, Oxford: Oxford University Press.

BOWLES, S.; GINTIS, H. (2002), “Social capital and community governance," Economic Journal, 112: 419-436.

BURT, R. S. (1992), Structural Holes: The Social Structure of Competition, Cambridge, MA: Harvard University Press.

COLEMAN, J. S. (1990), Foundations of Social Theory, Cambridge: Belknap Press of Harvard University Press.

DIPASQUALE, D.; GLAESER, E. (1999), “Incentives and social capital: are homeowners better citizens?", Journal of Urban Economics, 45: 354-384.

DUQUE, E. (2003) “A Identidade na pós-modernidade: um conceito histórico-hipotético”, Cadernos do Noroeste, 21, 1-2: 39-52.

DURLAUF, S. (2002), “On the empirics of social capital”, Economic Journal, 112: 459-479.

FUKUYAMA, F. (2000), A Grande Ruptura. A Natureza Humana e a Reconstituição da Ordem Social, Lisboa: Quetzal.

GOLDIN, C.; KATZ, L. (2001), "Human capital and social capital: the rise of secondary schooling in America 1910-1940”, in Rotberg (Ed.), Patterns of Social Capital, Cambridge University Press.

GUISO, L.; SAPIENZA, P.; ZINGALES, L. (2004), “The role of social capital in fi nancial development”, American Economic Review, 94(3): 526.

HELLIWELL, J.; PUTMAN, R. (1995), “Economic Growth and Social Capital in Italy", Eastern Economic Journal, 21: 295-307.

KNACK, S.; KEEFER, P. (1997), "Does Social Capital have an Economic Payoff? A Cross-Country Investigation”, Quarterly Journal of Economics, 112: 1251-1288.

LA PORTA, R. (et al.) (1997), "Trust in Large Organizations”, American Economic Review, Papers and Proceedings: 333-338.

LOURY, G. C. (1981), "Intergenerational transfers and the distribution of earnings", Econometrica, 49: 843-67. 
PEREIRA, S. B. (2007), "Processos tangíveis e intangíveis do desenvolvimento local”, Revista Económica do Nordeste, v. 38, n.․2: 289-305.

PUTMAN, R. (1993), Making Democracy Work, Princeton University Press.

PUTMAN, R. (1995), “Bowling Alone: America's Declining Social capital”, Journal of Democracy, 6 (January), 65-78.

PUTMAN, R. (2000), Bowling Alone: The collapse and revival of American community, Nova Iorque: Simon and Schuster.

PUTMAN, R. D. (1993b), “The prosperous community: social capital and public life”, American Prospect, 13: 35-42.

SCHIFF, M. (1992), “Social capital, labor mobility, and welfare”, Rationality and Society, 4: 157-75.

TOCQUEVILLE, A. (2006), De la démocratie en Amérique, Paris: Gallimard.

WOLFE, D. A. (2002), “Social Capital and Cluster Development in Learning Regions”, in J. Adam Holbrook e David A. Wolfe (eds.) Knowledge, Clusters and Regional Innovation: Economic Development in Canada, Montreal and Kingston: McGill-Queen's University Press for the School of Policy Studies, Queen's University.

\section{NOTES}

1. A este propósito, pode ler-se Lyda Judson Hanifan, particularmente ao descrever os centro comunitários de escolas rurais, e Jane Jacobs que explica a importância das redes sociais nos bairros urbanos; trabalhos que Fukuyama (2000) nos dá a conhecer.

2. Esta variável apresenta as seguintes opções de resposta: a) pode-se confiar na maioria das pessoas; b) todo o cuidado é pouco.

3. As opções de resposta variam entre 1 - muita confiança e 4 - nenhuma confiança. Nesta questão tivemos em conta as seguintes instituições: Igreja, Forças Armadas, Sistema Educativo, Imprensa, Sindicatos, Polícia, Parlamento, Administração Pública, Sistema de Segurança Social e Sistema Judicial, uma vez que estas são as comuns aos três anos em estudo.

4. Estes comportamentos podem ser justificados entre 1 (nunca) e 10 (sempre).

5. Questão: Diga, por favor, a importância que atribui a cada um dos seguintes aspetos na sua Vida - Amigos e conhecidos, medida entre 1 (muito importante) e 4 (nada importante).

6. Inquiriram-se os indivíduos sobre se eram membros e/ou voluntários de diferentes instituições apresentadas no EVS. Por motivos de operacionalização da questão nos três anos, não se teve em conta a pertença e/ou voluntariado em organizações de "Património, ambiente, ecologia, direitos dos animais" e "Grupos de consumo".

7. Os resultados de uma análise de variância mostram que existem diferenças no nível de capital social nos três anos em estudo: $\mathrm{F}(2,3737)=49,406, \mathrm{p}<0,001, \mathrm{~h} 2=0,03 . \mathrm{Em} \mathrm{1990}$, média $=1,77^{\mathrm{a}}$, em $1999=1,75^{\mathrm{a}}$ e em 2008, média $=1,92 \mathrm{~b}$; as médias com letras diferentes são estatisticamente diferentes. Recorremos ao método Scheffé por se tratar de um método mais conservador, permitindo controlar a taxa de erro para o conjunto total de comparações.

8. Em 90, tsexo $(1.183)=0,139$, ns; em 1999, tsexo $(998)=2,524$, ns e, em 2008, tsexo $(1.551)=$ $-0,457, \mathrm{~ns}$.

9. $\mathrm{Em} \mathrm{1990,} \mathrm{F}(2,1.184)=0,452, n s ;$ em 1999, $\mathrm{F}(2,998)=2,027$, ns; em 2008, $\mathrm{F}(2,1.552)=8,039, \mathrm{p}<$ $0,001, \mathrm{~h} 2=0,01$.

10. $\mathrm{Em} \mathrm{1990,} \mathrm{F}(2,1.126)=3,180, n s ;$ em 1999, $\mathrm{F}(2,696)=5,761, \mathrm{p}<0,005, \mathrm{~h} 2=0,02$; em 2008, $\mathrm{F}(2$, 763) $=14,227, \mathrm{p}<0,001, \mathrm{~h} 2=0,04$. 
11. $\mathrm{Em} \mathrm{1990,} \mathrm{F}(7,1184)=1,189, n s ;$ em 1999, $\mathrm{F}(7,999)=3,014, \mathrm{p}<0,05 ;$ em 2008, $\mathrm{F}(7,1552)=1,153$, ns.

12. Os resultados revelam diferenças no nível de capital social entre as idades em que os inquirido pensavam deixar de estudar: em 1990, F (9, 1097) = 4,005, p < 0,001, h2=0,03; em 1999, F $(9,840)=6,569, \mathrm{p}<0,001, \mathrm{~h} 2=0,07, \mathrm{e}$, em 2008, F $(9,1444)=5,776, \mathrm{p}<0,001, \mathrm{~h} 2=0,04$.

\section{ABSTRACTS}

Nas últimas décadas, tem-se assistido a uma crescente preocupação pelo desenvolvimento socialmente justo e sustentável; daí que as políticas de desenvolvimento que se têm delineado têm implícita uma preocupação de maior equidade e justiça, aprendendo do passado para assim projetar o futuro. Ora quem aprecia o horizonte, sem menosprezar o seu espólio e memória, vive o momento presente empenhado em viabilizar o porvir. Esta atitude implica uma postura comprometida dos cidadãos com o social. É desta forma comprometida, empreendedora e corresponsável que se compreende o capital social como meio de desenvolvimento sustentável. Com este estudo procura-se perceber até que ponto o capital social é um dos fatores determinantes do desenvolvimento sustentável. Indagam-se, para isso, os indicadores que melhor podem medir o capital social.

De uma forma mais específica, procura-se compreender até que ponto a sociedade portuguesa tem estimulado o capital social como recurso fundamental para o seu desenvolvimento. Esta questão é ilustrada a partir do inquérito do European Values Survey e, de uma forma longitudinal, analisamse os comportamentos dos portugueses entre 1990 e 2008. Os resultados mostram que os portugueses não estão ainda sensibilizados para a problemática do desenvolvimento sustentável, revelam posturas muito fechadas, pouco ou nada preocupadas com a construção de uma sociedade mais ativa e comprometida com o bem comum.

In the last decades, there has been a growing concern for an equitable and sustainable social development; hence development policies that have outlined have implied a concern for equity and justice, thus learning from the past to project the future. But those who appreciate the horizon, without diminishing the estate and the memory, live the present moment committed to facilitate the future. This position implies an attitude of citizens committed to the social. It is thus compromised and co-responsible entrepreneurship that comprises social capital as a means of sustainable development.

This study seeks to understand the extent to which social capital is one of the determinants of sustainable development. One wonders, for this, the indicators that best measure social capital. In more specific, we seek to understand how far society has encouraged the Portuguese capital as a fundamental resource for development. This point is illustrated from the European Values Survey and, in a longitudinal, analyzes the Portuguese behavior between 1990 and 2008. The results show that the Portuguese are not yet sensitized to the issue of sustainable development, reveal very closed postures, little or nothing concerned with the construction of a more active and committed to the common good.

$\mathrm{Au}$ long de ces dernières décennies, on a constaté une inquiétude croissante envers le développement socialement juste et durable, c'est pourquoi les politiques de développement tracées ont de façon implicite une plus grande préoccupation d'équité et de justice, à partir des 
leçons apprises du passé pour pouvoir ainsi projeter l'avenir. Cela étant, celui qui apprécie l'horizon, sans mépriser son patrimoine et sa mémoire, vit l'instant présent engagé pour rendre viable l'avenir. Cette attitude implique un (engagement social de la part des citoyens) comportement des citoyens engagés avec le social. C'est de cette forme compromise, engagée et responsable, que l'on comprend le capital social comme moyen de développement durable.

Avec cette étude, on vise comprendre jusqu'à quel point le capital social est un des facteurs déterminants du développement durable. On cherche, pour cela, les indicateurs qui mesurent le mieux le capital social.

Plus spécifiquement, on essaye de comprendre jusqu'où la société portugaise a stimulé le capital social comme ressource fondamentale pour son développement. Cette question est illustrée à partir de l'enquête de l' European Values Survey, et d'une façon longitudinale, on analyse le comportement des portugais entre 1990 et 2008. Les résultats montrent que les portugais ne sont pas encore sensibilisés aux problèmes du développement durable, qu'ils manifestent des comportements très renfermés, qu'ils sont peu ou nullement préoccupés à la construction d'une société plus active et engagée avec le bien commun.

\section{INDEX}

Mots-clés: Capital Social; Développement Durable; Intelligence sociale; Réseaux sociaux; Identité; Valeurs.

Keywords: social capital, sustainable development, social intelligence, social networks, identity, values.

Palavras-chave: capital social, desenvolvimento sustentável, inteligência social, redes sociais, identidade, valores.

\section{AUTHOR}

\section{EDUARDO DUQUE}

Universidade Católica Portuguesa e Centro de Investigação em Ciências Sociais da Universidade do Minho

eduardoduque@ics.uminho.pt 